\title{
Cocaine locomotor activation, sensitization and place preference in six inbred strains of mice
}

Amy F Eisener-Dorman', Laura Grabowski-Boase ${ }^{2}$ and Lisa M Tarantino ${ }^{1 *}$

\begin{abstract}
Background: The expanding set of genomics tools available for inbred mouse strains has renewed interest in phenotyping larger sets of strains. The present study aims to explore phenotypic variability among six commonlyused inbred mouse strains to both the rewarding and locomotor stimulating effects of cocaine in a place conditioning task, including several strains or substrains that have not yet been characterized for some or all of these behaviors.

Methods: C57BL/6J (B6), BALB/CJ (BALB), C3H/HeJ (C3H), DBA/2J (D2), FVB/NJ (FVB) and 129S1/SvImJ (129) mice were tested for conditioned place preference to $20 \mathrm{mg} / \mathrm{kg}$ cocaine.

Results: Place preference was observed in most strains with the exception of D2 and 129. All strains showed a marked increase in locomotor activity in response to cocaine. In BALB mice, however, locomotor activation was context-dependent. Locomotor sensitization to repeated exposure to cocaine was most significant in 129 and D2 mice but was absent in FVB mice.

Conclusions: Genetic correlations suggest that no significant correlation between conditioned place preference, acute locomotor activation, and locomotor sensitization exists among these strains indicating that separate mechanisms underlie the psychomotor and rewarding effects of cocaine.
\end{abstract}

\section{Background}

The devastating effects of drug addiction on the lives of those who struggle with it and the social and economic implications for society as a whole are staggering. Faced with this challenge, understanding the biological pathways that predispose individuals to addiction to cocaine (and other drugs) is a top priority in the research community. The perception that genetic background influences the predisposition to abuse drugs is supported by studies in humans [1] and in animal models [2-4]. While no animal model exists that recapitulates the entire spectrum of the drug abuse syndrome in humans, animal models do exist for the study of specific drugrelated behaviors, including initial sensitivity (as measured by drug-induced locomotor behavior), sensitization and drug reward and reinforcement paradigms.

Conditioned place preference (CPP) has been established as a standard procedure for assessing the rewarding effects of drugs in rodent models. In the CPP

\footnotetext{
* Correspondence: lisat@med.unc.edu

'Department of Psychiatry, University of North Carolina, Chapel Hill, NC, USA Full list of author information is available at the end of the article
}

paradigm, rodents learn to associate a specific environmental context with the effects of a drug stimulus. Place conditioning confers many advantages in the study of drug-induced motivational responses, including the short duration and relative simplicity of the procedure in comparison with reinforcement models such as selfadministration. CPP also provides the opportunity to measure the initial acute response and sensitization or tolerance to the locomotor stimulating effects of a drug following repeated exposure [5,6]. In addition, CPP is measured in the absence of drug-related physiological confounds such as locomotor and sensory effects [5]. Encountering environments and stimuli previously associated with drug use is one of the most common triggers for relapse in humans $[7,8]$, and the CPP paradigm specifically addresses the effects of context-specific exposures on drug reward and drug-seeking behaviors in animal models [9].

Drug-induced behaviors, including CPP, have a significant genetic component as demonstrated by the large degree of phenotypic variability among inbred mouse strains $[4,10]$. The goal of the present study was to

\section{Biomed Central}


expand upon the current literature by investigating drug-induced sensitivity, sensitization and place conditioning in six commonly used and genetically diverse inbred mouse strains. Several of these strains have already been characterized for CPP, cocaine locomotor activation and sensitization [4], while others, including FVB/NJ and substrains of 129 (129S1/SvImJ) and BALB $(\mathrm{BALB} / \mathrm{cJ})$, have not previously been studied in the place preference paradigm. Here, we present strain-specific differences that confirm, contradict, and expand upon previously reported inbred strain responses to cocaine.

\section{Methods}

\section{Animals}

Male mice from six inbred strains (129S1/SvImJ (129), $C 57 B L / 6 J$ (B6), $B A L B / c J$ (BALB), C3H/HeJ (C3H), DBA/ $2 J(D 2)$ and $F V B / N J(F V B))$ were obtained from the inhouse breeding colony at the Genomics Institute of the Novartis Research Foundation (GNF). Inbred strains for the GNF breeding colony were initially purchased from the Jackson Laboratory (Bar Harbor, ME, USA), and breeder stocks were replenished every seventh generation to limit genetic drift. Mice were group-housed and maintained in an AAALAC-accredited, specific pathogen-free (SPF) barrier colony in ventilated cages (Thoren Caging Systems, Hazelton, PA, USA) on a 12-hour light-dark cycle (lights on at 6:00 A.M.). Irradiated food (Pico rodent chow 20; Purina, St. Louis, MO, USA) and water were provided ad libitum. Mice were between 59 and 70 days of age at the onset of testing, and all behavioral testing occurred between 8:00 A.M. and 12:00 P.M.

Sixteen B6 mice and eight mice from each of the remaining five strains were tested in the conditioned place preference procedure described below. Groups of mouse strains were tested in three separate testing sessions over the course of two months, and all mice in a group were tested on the same day. With the exception of B6, all mice of each strain were tested in the same session and different strains were tested in each of the three sessions. Two sets of B6 mice ( 8 mice per set) were tested in the first and last sessions as a control for temporal effects across sessions.

Male mice were chosen for testing to mitigate the variability observed in females due to estrous cycle [11-13].

All procedures were approved by the GNF Institutional Animal Care and Use Committee and followed the guidelines set forth by the National Institutes of Health (NIH) Guide for the Care and Use of Laboratory Animals

\section{Drugs}

Cocaine was dissolved in saline $(0.9 \% \mathrm{NaCl})$. A $20 \mathrm{mg} /$ $\mathrm{kg}$ dose of cocaine was used to obtain a moderate cocaine-induced response across strains, as previous studies suggest this dose is sufficient to induce a drug response in many strains $[4,14,15]$. Immediately following an intraperitoneal (i.p.) injection with cocaine or saline, each animal was placed in the appropriate chamber of the CPP apparatus.

\section{Apparatus}

Conditioned place preference testing was conducted using a three-chambered conditioned place preference apparatus $(46.5 \times 12.7 \times 12.7 \mathrm{~cm}$; MED-CPP-MSAT, Med Associates) in a sound-attenuating enclosure (ENV-016MD, Med Associates). The apparatus consisted of a grey center compartment $(7.2 \times 12.7 \mathrm{~cm})$ with a smooth PVC floor and two choice compartments $(16.8 \times 12.7 \mathrm{~cm})$ on either side. One compartment was all black with a stainless steel grid rod floor consisting of $3.2 \mathrm{~mm}$ rods placed on $7.9 \mathrm{~mm}$ centers and the other was all white with a $6.35 \times 6.35 \mathrm{~mm}$ stainless steel mesh floor. Compartments were separated by guillotine doors, which were left open to permit free exploration of the full apparatus during pre-test on Day 1 and the testing phase on Day 10 but were closed during training days. Two identical CPP apparatuses were used and each apparatus had two training chambers (black and white) for a total of four training chambers. Each mouse was tested in the same apparatus and the same training chamber throughout the experiment.

Mouse movement in the apparatus was detected by six infrared photobeams (spaced $2.8 \mathrm{~cm}$ apart and $1.0 \mathrm{~cm}$ from the end wall) in each choice compartment and three (spaced $2.8 \mathrm{~cm}$ apart) in the center compartment. Photobeams mounted $1.8 \mathrm{~cm}$ above the apparatus floor captured horizontal movement. The absence of z-axis photobeams did not permit detection of vertical movement, such as rearing. Activity was captured by automated data collection as movement counts. Movement counts are defined as consecutive beam breaks within a chamber to detect horizontal forward locomotion while excluding stereotypic behavior. Entrance into a chamber was recorded when the second photobeam into the chamber was broken. Time spent in each compartment was recorded in seconds.

\section{Conditioned place preference procedure}

The place preference procedure consisted of three phases, as outlined below and in Figure 1.

\section{Pre-test phase}

The purpose of the pre-test was to habituate the animals to the novelty and stress associated with the apparatus, handling and injection prior to conditioning, as well as to identify initial chamber preferences. For the pre-test, all mice received an i.p. saline injection immediately prior to placement in the apparatus for 20 minutes. 


\begin{tabular}{|c|c|c|c|c|c|c|c|c|c|c|}
\hline \multirow{2}{*}{$\begin{array}{r}\text { Phase } \\
\text { Treatment }\end{array}$} & \multirow{2}{*}{$\begin{array}{c}\text { pre-test } \\
\text { saline }\end{array}$} & \multicolumn{8}{|c|}{ conditioning } & \multirow{2}{*}{$\frac{\text { test day }}{\text { saline }}$} \\
\hline & & saline & cocaine & saline & cocaine & saline & cocaine & saline & cocaine & \\
\hline Da & & & & & & & & & & \\
\hline
\end{tabular}

Figure 1 Timeline of the place preference study

Mice were placed in the grey center compartment at the beginning of the pre-test but were allowed to move freely between compartments. The total time spent in each of the three chambers was recorded and then calculated as a percentage of the total test duration. The percent time spent in the black and white chambers only, not including the grey chamber, was also calculated and used as the pre-conditioning value for place preference analysis.

\section{Conditioning phase}

For the conditioning procedure, animals from each strain were randomly assigned to one of two conditioning subgroups. Mice in one subgroup $(\mathrm{N}=4$ per strain; $\mathrm{B} 6 \mathrm{~N}=8$ ) received cocaine paired with the black chamber and saline paired with the white chamber. Mice in the second subgroup $(\mathrm{N}=4$ per strain; $\mathrm{B} 6 \mathrm{~N}=8$ ) received cocaine paired with the white chamber and saline paired with the black chamber. On days 2, 4, 6 and 8 , mice were injected with saline and placed in the unpaired chamber. On days 3, 5, 7 and 9, mice were injected with cocaine and placed in the drug-paired chamber. Conditioning took place across eight subsequent days, and trials were 30 minutes in duration (one trial per day). Movement counts in the black and white chambers were recorded.

\section{Test day}

For the testing phase on Day 10, mice received an i.p. injection of saline immediately prior to placement in the grey center compartment of the apparatus and were allowed to move freely between the compartments for the duration of the 30-minute testing trial. The primary dependent variable was percent time spent in the cocaine-paired chamber during the testing trial, which was calculated by dividing time spent in the drug-paired chamber by total time spent in the black and white chambers and multiplying by 100 . Conditioned place preference was measured as percent time spent in the cocaine-paired chamber before (Day 1) and after (Day 10) conditioning, and the development of place preference was defined as a significant difference between preand post-conditioning values. Movement counts in the black and white compartments were also recorded.

\section{Statistical analysis}

All data were analyzed using the SPSS statistical package (version 16.0 for Macintosh, SPSS, Chicago IL, USA).
Multivariate analysis of variance (ANOVA) was used to analyze the effect of strain for each behavioral measure. Dependent variables differed based on behavioral measure and included percent time spent in each chamber for equipment bias assessment and percent time spent in the cocaine-paired chamber for place preference. Locomotor activity (recorded as movement counts) was assessed for acute locomotor response, sensitization and on the test day (Day 10). Day of testing was included as an independent variable to assess the effects of cocaine on time spent in the cocaine-paired chamber and also for locomotor activity over multiple days of testing (acute and sensitized locomotor activity). Based on results from the pre-test session indicating that the equipment was unbiased, data were collapsed across training chambers for analysis of place preference. However, locomotor activity during the conditioning phase differed between black and white chambers for some strains; therefore, chamber was included as an independent variable for activity analyses. Locomotor activity was also used as a covariate in the CPP analysis. Posthoc Tukey HSD and t-tests were employed for individual post-hoc comparisons.

The two groups of B6 mice were analyzed by one-way ANOVA with group as the independent variable. Dependent variables included acute locomotor response, sensitization and place preference.

Genetic correlations were assessed using partial correlation of percent CPP (Day 10 - Day 1), total locomotor activity in the black and white chambers on the test day (Day 10 movements), cocaine locomotor sensitization (Day 9 - Day 3 movements), acute locomotor response to cocaine (Day 3 - Day 2 movements) and salineinduced basal locomotor activity (Day 2 movements), therefore controlling for the effects of strain. Percent time spent in the drug-paired chamber on Day 1 was subtracted from percent time spent in the drug paired chamber on Day 10 to yield the CPP value used for correlation analyses.

\section{Results}

\section{Pre-test chamber bias}

Training chamber bias was examined by two-way ANOVA (strain and chamber) of time spent in each of the three chambers. A significant main effect of chamber was observed $\left(\mathrm{F}_{(2,167)}=16.6 ; p<0.001\right)$ as well as a 
strain by chamber interaction $\left(\mathrm{F}_{(10,167)}=4.5 ; p<0.001\right)$. Tukey post-hoc comparisons of the three chambers indicated that there was no difference in the time mice spent in the black and white chambers $(p=0.374)$ (Figure 2). Therefore, mice were assigned to the training chamber in an unbiased manner and place preference data analysis was conducted on the group as a whole regardless of training chamber.

Visual inspection of Day 1 data indicated that three out of eight 129 mice spent almost $100 \%$ of the time in a single chamber during the pre-test, and one mouse spent over $83 \%$ (data not shown). Therefore, 129 mice were excluded from overall analysis of place preference to avoid skewing interstrain comparisons due to 129 strain-specific equipment bias effects. Place preference in the 129 mice was analyzed separately from the other strains with the four outliers excluded.

\section{B6 Control Groups}

One-way ANOVA identified no significant effect of B6 group on either CPP $\left(\mathrm{F}_{(1,15)}=0.21 ; p>0.05\right)$ or sensitization $(\mathrm{F}(1,15)=0.13 ; p>0.05)$. A significant effect of acute locomotor response to cocaine was observed ( $\mathrm{F}$ $(1,15)=4.9 ; p<0.05)$. Animals in Group 1 show greater acute sensitivity to cocaine than animals in Group 2. A closer examination of the data indicates that the groups do not differ on Day 2 baseline locomotor activity $(\mathrm{t}(14)$ $=0.26 ; p>0.05)$, but B6 animals from Group 1 are significantly more activated by cocaine on Day $3(\mathrm{t}(14)=$ $2.4 ; p<0.05)$. Extending the analysis to the entire experiment, we observed that the two groups do not differ for saline-induced locomotor behavior (Days 2, 4, 6 and 8) but consistently differ for cocaine-induced locomotor behavior (Days 3, 5, 7 and 9) (data not shown).

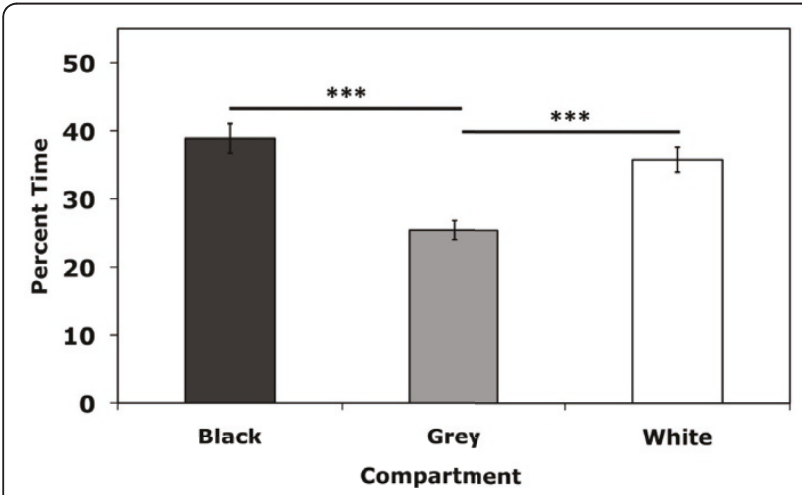

Figure 2 Initial bias for each chamber of the three-chamber place preference apparatus during the pre-test session. All strains were included in the analysis. Separate analysis excluding 129 mice yielded similar results (data not shown). Error bars are SEM. ${ }^{* * *} p<0.001$.

\section{Cocaine place preference}

A two-way ANCOVA (strain by day with locomotor activity as the covariate) yielded a significant effect of day $\left(\mathrm{F}_{(1,95)}=7.3 ; p<0.01\right)$ indicating that mice spent more time in the cocaine-paired chamber on Day 10 following conditioning than on Day 1 during the pre-test. The effect of locomotor activity was not significant ( $\mathrm{F}$ $(1,95)=0.78 ; p>0.05)$. Strain $\left(\mathrm{F}_{(4,95)}=1.5 ; p>0.05\right)$ and strain by day interaction effects $\left(\mathrm{F}_{(4,95)}=1.2 ; p>0.05\right)$ were also not observed indicating that no strain differences in place preference were detected. Post-hoc t-tests, however, showed that D2 mice did not spend significantly more time in the cocaine-paired chamber on Day 10 than on Day $1(t(14)=-0.09 ; p>0.05$; Figure 3).

129 mice spent more time in the drug-paired chamber after conditioning, but the difference was not significant $(\mathrm{t}(14)=-1.5 ; p>0.05)$ indicating that this substrain of 129 does not exhibit place preference to $20 \mathrm{mg} / \mathrm{kg}$ under these experimental conditions (Figure 3). However, variability in 129 mice was much higher than in other strains, possibly due to locomotor hypoactivity often observed in this inbred strain.

\section{Chamber effects on locomotor activity}

Differences in locomotor activity in the black and white chambers are an important consideration when analyzing locomotor response to cocaine in the CPP procedure. Although strains spent equal amounts of time in the black and white chambers on Day 1, two-way ANOVA (strain $\times$ chamber) of locomotor movements in the CPP apparatus during the pre-test indicated that there were significant main effects of strain $\left(\mathrm{F}_{(5,111)}=\right.$ $28.2 ; p<0.001)$ and chamber $\left(\mathrm{F}_{(1,111)}=39.1 ; p<0.001\right)$, as well as a significant interaction effect $\left(\mathrm{F}_{(5,111)}=2.5 ; p\right.$ $<0.05)$. Strain differences were reflective of normal variation in locomotor activity among inbred strains and had the following pattern: $129=\mathrm{C} 3 \mathrm{H}<\mathrm{B} 6=\mathrm{D} 2=\mathrm{FVB}$ $<$ BALB. Overall, mice were more active in the black chamber. Post-hoc t-tests indicated that increased activity in the black chamber was only significant for B6 ( $\mathrm{t}$ $(30)=6.8 ; p<0.001)$, D2 $(\mathrm{t}(14)=3.9 ; p<0.01)$ and FVB $(\mathrm{t}(14)=5.5 ; p<0.001)$ strains.

However, locomotor activity differences in black vs. white chambers were no longer significant on the second day of testing when mice were restricted to the unpaired chamber in which they received saline and before their first exposure to cocaine. On Day 2, only strain effects were significant $\left(\mathrm{F}_{(5,55)}=6.6 ; p<0.001\right)$ and no chamber $\left(\mathrm{F}_{(1,55)}=0.75 ; p=0.39\right)$ or interaction effects $\left(\mathrm{F}_{(5,55)}=1.3 ; p=0.27\right)$ were observed. Nevertheless, cocaine-paired chamber was included as an independent variable in all locomotor activity analyses to assess the effect of chamber on the dependent variable. 


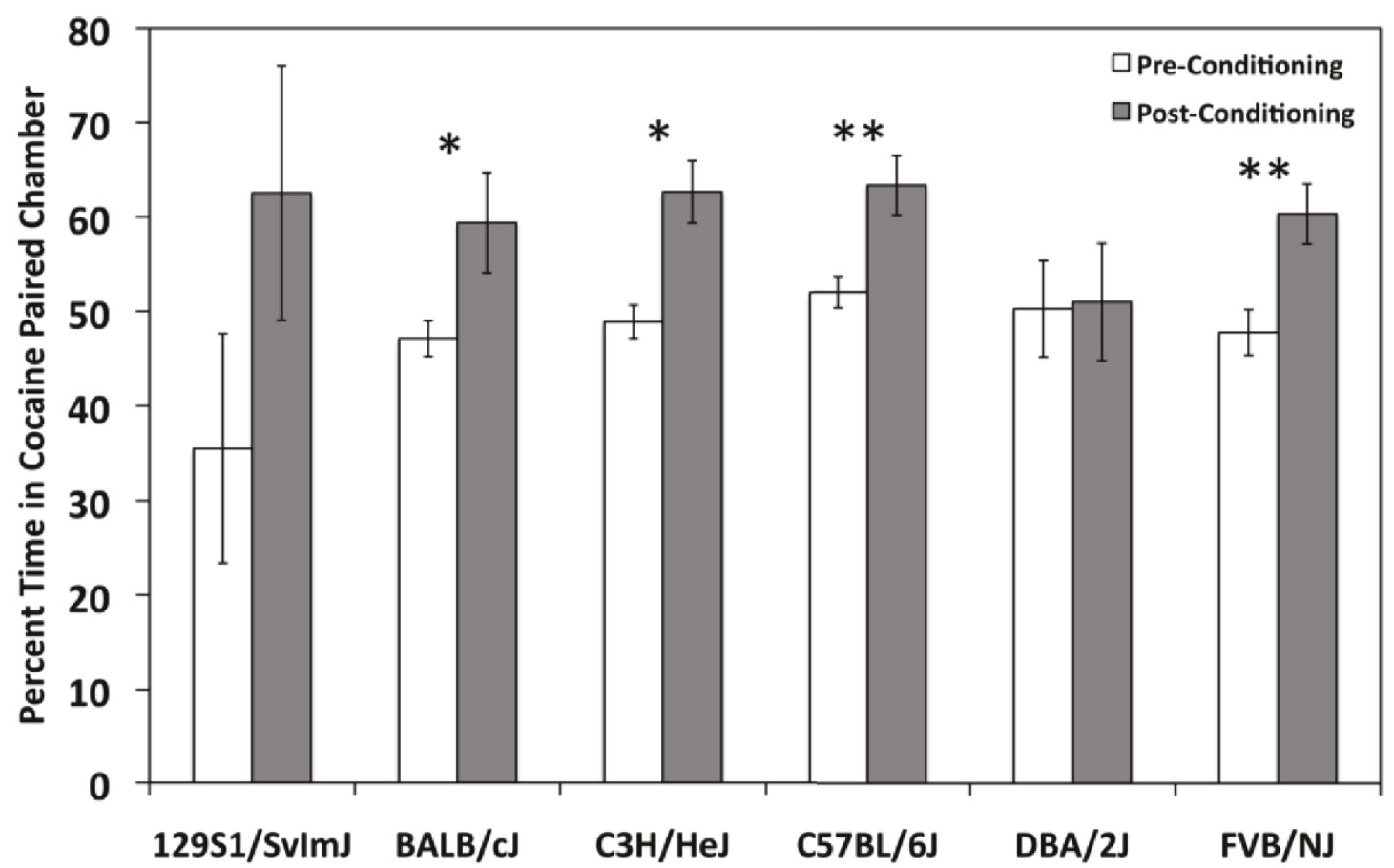

Figure 3 Cocaine-induced place preference in six inbred strains. Percent time spent in the cocaine-paired chamber both pre- (white bars) and post-conditioning (grey bars) is shown. Error bars are SEM. ${ }^{*} p<0.05,{ }^{* *} p<0.01$.

\section{Acute locomotor response to cocaine}

Acute locomotor response was measured by comparison of locomotor activity on Day 2 (saline) and Day 3 after the first exposure to cocaine. Significant strain $\left(\mathrm{F}_{(5,111)}=\right.$ $6.46 ; p<0.001)$ and day of testing $\left(\mathrm{F}_{(1,111)}=62.1 ; p<\right.$ $0.001)$ effects and a significant strain by day of testing interaction effect $\left(\mathrm{F}_{(5,111)}=3.23 ; p<0.05\right)$ were observed by two-way ANOVA. Post-hoc t-tests of individual strains indicate that all strains showed a significant increase in locomotor activity in response to acute cocaine with the exception of BALB (Figure 4). No effect of cocaine-paired chamber was observed $\left(\mathrm{F}_{(1,111)}=\right.$ $0.19 ; p=0.66)$ indicating that acute locomotor activation was not affected by the chamber in which the mice received cocaine.

\section{Cocaine locomotor sensitization}

Locomotor sensitization for all strains was assessed by examining locomotor behavior across all four days of cocaine treatment. Significant main effects of strain (F $(5,223)=18.2 ; p<0.001)$ and day of treatment $\left(\mathrm{F}_{(3,223)}=\right.$ $5.9 ; p<0.01)$ but no strain by day interaction effect (F $(15,223)=0.42 ; p=0.97)$ were observed by ANOVA. Cocaine-induced locomotor activation increased with repeated treatments across all strains indicating that sensitization was occurring. Post-hoc Tukey comparisons collapsed across strains indicate that locomotor behavior increased significantly by the third cocaine challenge.
However, although most strains showed a pattern of increasing locomotor response with repeated exposures, post-hoc Tukey's analysis by strain indicates that only 129 and D2 mice showed significant increases in locomotor activity after the initial dose of cocaine (Figure 5).

Locomotor activity in response to saline was also assessed by two-way ANOVA, and a main effect of strain was observed $\left(\mathrm{F}_{(5,223)}=18.7 ; p<0.001\right)$ but no day of treatment $\left(\mathrm{F}_{(3,223)}=1.5 ; p=0.206\right)$ or strain by day interaction effects $\left(\mathrm{F}_{(15,223)}=1.1 ; p=0.380\right)$. However, no generalized locomotor changes across days of saline treatment were observed (Figure 5).

An effect of cocaine-paired chamber was also observed during both cocaine treatment days $\left(\mathrm{F}_{(1,223)}=10.9 ; p<\right.$ $0.01)$ and saline treatment days $\left(\mathrm{F}_{(1,223)}=8.8 ; p<0.01\right)$, as well as strain by cocaine-paired chamber interaction effects $\left(\mathrm{F}_{(5,223)}=10.2 ; p<0.001\right.$ and $\mathrm{F}_{(5,223)}=4.3 ; p<$ 0.01 , respectively). These data indicate that inbred strains differed in their locomotor behavior depending upon the chamber to which they were restricted during the conditioning trials. Several strains, including B6, $\mathrm{C} 3 \mathrm{H}$ and $\mathrm{FVB}$, appear to have a generalized increase in locomotor activity in the black chamber regardless of treatment with either saline or cocaine (Figure 6). D2 mice showed no difference in activity in either black or white chambers. Two strains in particular, BALB and 129, exhibited a chamber and/or drug-dependent locomotor response. 129 mice showed reciprocal differences 

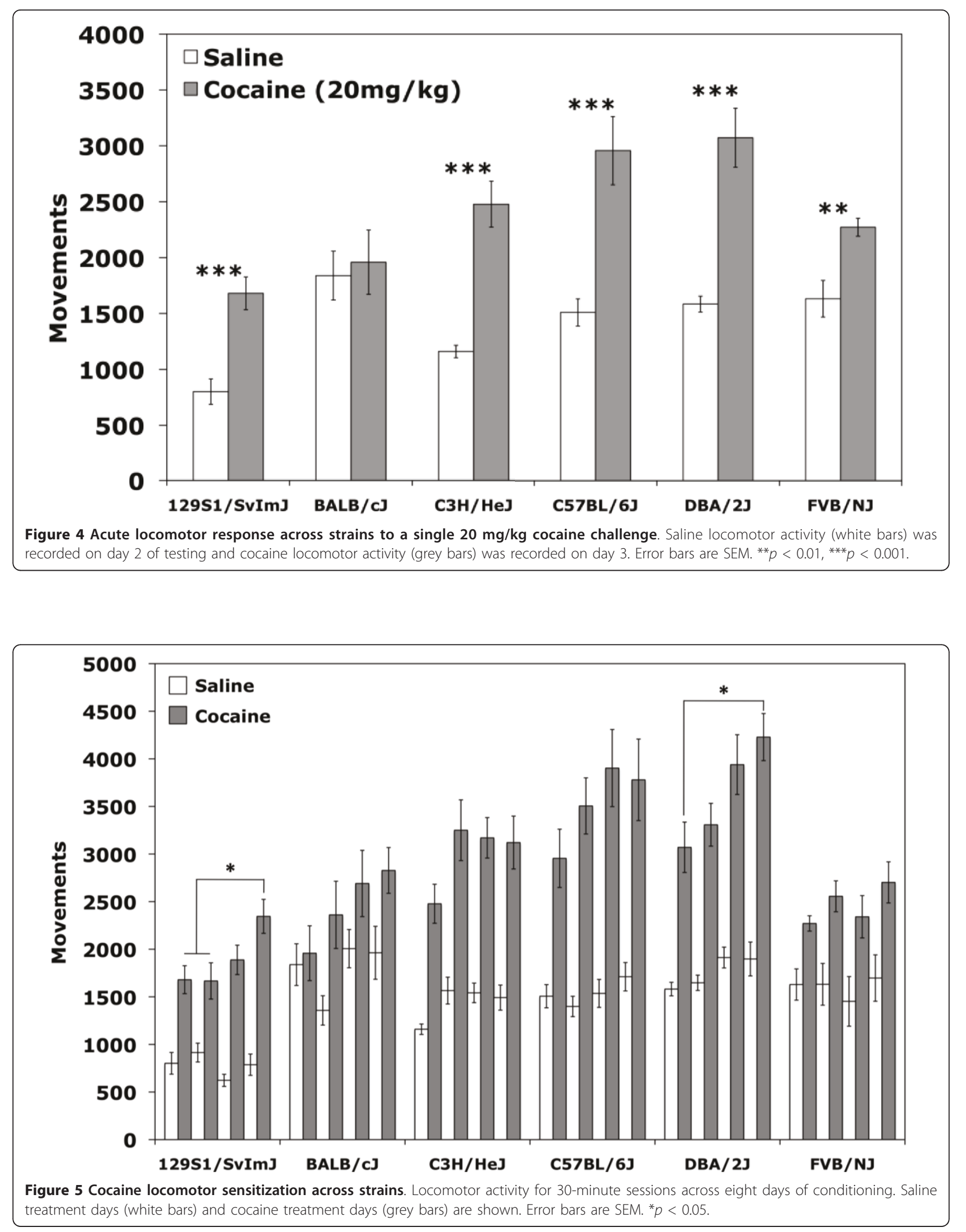


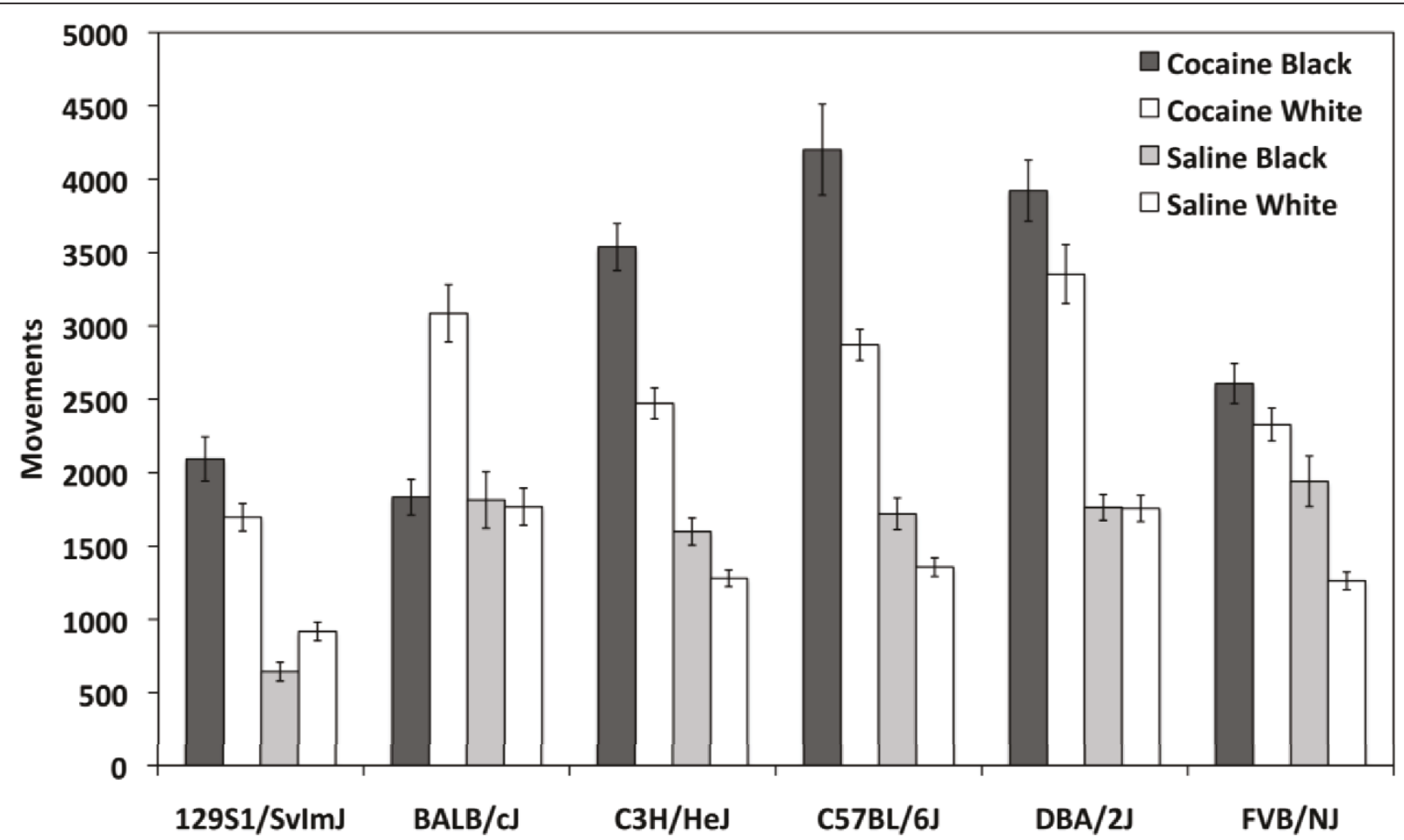

Figure 6 Effect of training chamber on locomotor activity during repeated exposures to either cocaine or saline. Bars represent locomotor activity of groups of mice ( $N=4$ per strain; $B 6 N=8$ ) exposed to cocaine and saline in either the black or white chamber. The first white bar is cocaine-induced activity in white chambers. The second white bar is saline-induced activity in white chambers. Error bars are SEM. B6, $\mathrm{C} 3 \mathrm{H}$ and FVB exhibited more locomotor activity in the black chamber regardless of treatment with either saline or cocaine. D2 mice showed no difference in activity in either black or white chambers. 129 mice showed reciprocal differences in activity and were more active in the black chamber after exposure to cocaine and more active in the white chamber after exposure to saline. BALB mice showed similar amounts of locomotor activity in response to saline in both the black and white chambers and showed a significantly higher response to cocaine only when it was administered in the white chamber.

in activity and were more active in the black chamber after exposure to cocaine and more active in the white chamber after exposure to saline. BALB mice showed similar amounts of locomotor activity in response to saline in both the black and white chambers and, surprisingly, showed a significantly higher response to cocaine only when it was administered in the white chamber (Figure 6).

\section{Correlation analyses}

Partial correlations were performed to assess relationships between the stimulatory and rewarding effects of cocaine while controlling for strain effects. The effect of locomotor activity on the test day was assessed with regard to its effect on place preference for all strains except 129. A partial correlation of total locomotor movements on Day 10 and percent place preference indicated that activity did not have a significant effect on place preference behavior (Table $1 ; \mathrm{r}(45)=0.21 ; p>$ $0.05)$.

The relationships between acute locomotor stimulation, sensitization and CPP were also assessed by partial correlation and the results presented in Table 1. No significant correlations were observed.

A relationship between baseline and acute locomotor activity in response to cocaine has been previously reported [16,17]. Partial correlation analysis of salineinduced baseline activity and cocaine-induced locomotor activation did show a significant negative correlation ( $\mathrm{r}$ $(45)=-0.40 ; p<0.01)$ indicating that strains with higher baseline locomotor activity exhibited lesser increases in locomotor response to cocaine.

\section{Discussion}

In this study of six commonly-used inbred strains, our results show significant strain differences in locomotor response to an acute cocaine challenge, in addition to locomotor sensitization and conditioned place preference to cocaine for most strains. Despite the absence of CPP in 129S1/SvImJ and DBA/2J mice, these strains exhibited robust acute locomotor and sensitization responses to $20 \mathrm{mg} / \mathrm{kg}$ of cocaine. Both $\mathrm{FVB} / \mathrm{NJ}$ and $\mathrm{BALB} / \mathrm{c}$ ) developed CPP, but FVB showed low acute locomotor activation and no significant sensitization, 
Table 1 Partial correlations of behavioral variables controlling for strain

\begin{tabular}{llccc}
\hline & Acute Locomotor & $\begin{array}{c}\text { Locomotor } \\
\text { Stimulation }\end{array}$ & $\begin{array}{c}\text { Day 10 } \\
\text { Sovitization }\end{array}$ & $\begin{array}{c}\text { Baseline Locomotor } \\
\text { Activity }\end{array}$ \\
\hline Locomotor Sensitization & $r$ & -0.077 & & \\
& $p$ & 0.607 & & \\
& $d f$ & 45 & 0.153 & \\
\hline Day 10 Movements & $r$ & 0.004 & 0.303 & \\
& $p$ & 0.976 & 45 & 0.487 \\
Baseline Locomotor & $d f$ & 45 & -0.035 & 0.001 \\
Activity & $r$ & -0.402 & 0.815 & 45 \\
& $p$ & 0.005 & 45 & 0.214 \\
\hline Place Preference & $d f$ & 45 & 0.055 & 0.149 \\
& $r$ & -0.057 & 0.711 & 45 \\
\hline
\end{tabular}

whereas BALB showed no acute locomotor activation but strong context-specific cocaine sensitization. C57BL/ 6J and $\mathrm{C} 3 \mathrm{H} / \mathrm{HeJ}$ mice developed $\mathrm{CPP}$ as well as strong acute locomotor stimulatory and sensitization responses. The results of this study highlight the significant role of genetic background in determining behavioral responses to drugs of abuse, such as cocaine.

It should be noted that these results are limited to a single dose of $20 \mathrm{mg} / \mathrm{kg}$ and dose-dependent differences in place preference have been noted by others [18-20]. In addition, other behaviors such as rearing or stereotypies may interfere with the measurement of locomotor behavior. In general, peripherally-administered cocaine results in decreased rearing behavior, although this effect is strain- and dose-dependent [21,22]. Measurement of rearing behavior is not possible with our CPP apparatus and strain differences in rearing behavior could have affected locomotor response; however, at least one study has shown dissociation between cocaine's effects on rearing and locomotor behaviors [23]. Stereotypy in response to cocaine is also dose- and strain-dependent. Stereotypic responses to repeated, but not acute, injections of cocaine have been reported for B6 and D2 strains [24,25]. Strain differences in stereotypy can also interfere with locomotor responses and may play a factor in our results. Regardless, strain differences in locomotor activity due to stereotypy still reflect real differences in behavioral sensitivity to cocaine.

Finally, differences in cocaine-induced locomotor activation in the B6 groups suggest that the strain differences in locomotor response to cocaine could be confounded by temporal differences. However, we do not believe this to be the case based on the congruence of our strain data with published studies on cocaine locomotor activation.
Our study includes three strains or substrains that, to the best of our knowledge, have not yet been characterized for cocaine-induced CPP - FVB/NJ, 129S1/SvImJ and BALB/CJ. FVB mice and 129 ES cells are frequently used in the generation of transgenic and knockout lines, therefore, characterization of these strains' responses to the rewarding and stimulating properties of cocaine has significant implications for behavioral effects related to genetic background. Similar to the results of a study by Zombeck et al. [26], we found that acute locomotor response to $20 \mathrm{mg} / \mathrm{kg}$ cocaine in FVB mice is lower relative to the other strains, except BALB (Figure 4). FVB mice also do not show significant sensitization to repeated doses of cocaine under our experimental conditions (Figure 5). Although acute locomotor response to cocaine is relatively low, FVB mice do show robust place preference (Figure 3) indicating that this strain is sensitive to the rewarding effects of cocaine.

Cocaine-mediated behaviors in the 129S1 strain have not yet been reported; however, several other 129 substrains have been characterized for cocaine locomotor activity with mixed results [21,25,27-29]. Taken together, these results suggest that locomotor activation in 129 mice may be substrain or dose-dependent and may be sensitive to experimental parameters.

Studies assessing the rewarding effects of cocaine in 129 substrains are more variable with some studies observing no place preference [28] and others observing significant place preference [27]. We found that 129S1 mice do not show significant place preference to $20 \mathrm{mg} /$ $\mathrm{kg}$ cocaine, similar to the observation of Miner [28] although at lower doses. Our results may have been influenced by the baseline hypoactivity observed in 129S1 mice, which are extremely inactive in many behavioral assays [30-32]. These data underscore the 
importance of considering the unique behavioral characteristics of different inbred mouse strains that may influence experimental outcomes.

As we observed in the 129 mice, the role of locomotor activity in behavioral assays cannot be overlooked. The extent to which basal locomotor activity correlates with initial drug sensitivity has been examined with varied results. Several studies report no correlation between acute locomotor stimulation and baseline locomotion $[33,34]$, while others observe a significant correlation $[16,17]$. In our sample, baseline locomotor activity does predict acute response to cocaine, as demonstrated by the correlation between saline-induced and acute cocaine-induced activity.

Correlations between activity and CPP may reflect interference between conditioned activity and the development of place preference or strain differences in either basal or psychostimulant-induced locomotor response during training [35-37]. Conditioned activity does not appear to influence CPP in our group, as we did not observe a correlation between CPP and locomotor activity on the test day.

The measurement of acute response, sensitization and the rewarding effects of cocaine allow us to examine one prominent hypothesis of addiction. The incentivesensitization model of drug craving suggests that chronic drug abuse causes hypersensitivity of the underlying brain circuitry as measured by sensitization, which exacerbates incentive salience and may explain the compulsive drug-seeking that drives addiction [38]. Similar to observations by Cunningham et al. [14], our data do not appear to support theories of a positive link between drug craving and sensitization [38] or the rewarding and stimulating effects of drugs [39], as we observed no correlation between place preference and either acute locomotor stimulation or sensitization.

Similar to our results, most studies in BALB mice report low levels of locomotor activation or no effect at all in response to cocaine [22,26,40-46]. Further, BALB mice reportedly do not develop place preference to moderate cocaine doses [18]. However, the level of locomotor activation in our study was dependent on the chamber in which the cocaine was administered. BALB mice receiving cocaine in the white chamber showed significant locomotor activation that exceeded the responses of other strains whereas BALB mice receiving cocaine in the black chamber did not display locomotor activation (Figure 6). This level of activation was not observed after acute administration of cocaine but was observed on all subsequent days of cocaine administration in the white chamber (Figure 7) indicating that the locomotor activation developed upon repeated drug dosing. Taken together, these data indicate that a specific interaction between the drug and the environment is

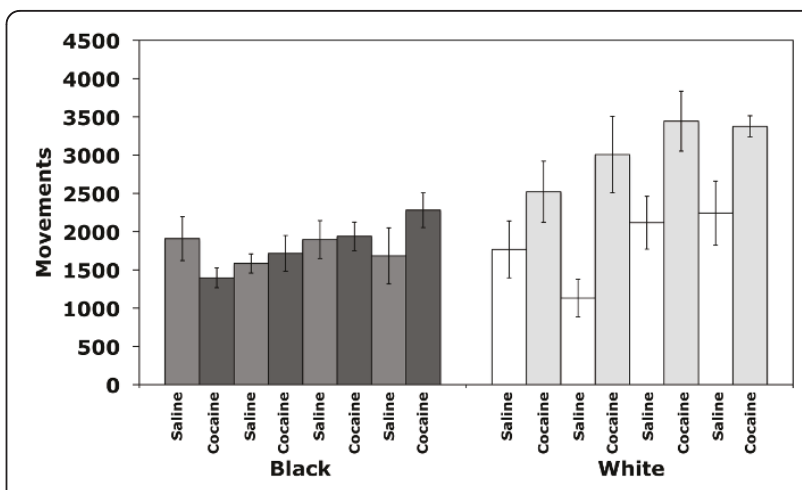

Figure 7 White vs. black chamber effect on cocaine-induced locomotor activity and sensitization observed for BALB/cJ mice in the CPP apparatus. Results are separated by chamber in which mice received cocaine during conditioning trials. Conditioning days and treatment are shown sequentially along the $x$-axis. Error bars are SEM.

occurring, resulting in context-dependent sensitization in BALB mice.

The context in which a drug is experienced can significantly influence both acute and sensitized responses to the drug $[47,48]$. Context-dependent sensitization has also been attributed to associative learning or increased stress $[47,49-51]$. It is possible that the white chamber may be anxiogenic for BALB mice, resulting in greater sensitization. However, this is unlikely since BALB mice spend equivalent amounts of time in both chambers during the pre-test session on Day 1. Alternatively, features of the white chamber may cause BALB mice to more readily associate the context with the drug effects. Willner et al. have shown that the extent of sensitization is determined by the behavior elicited by the drug [52], thus BALB mice may develop greater sensitization as a result of a greater stimulatory response to cocaine in the white chamber. Acute locomotor response to cocaine is certainly higher for BALB mice in the white chamber (Figure 7) but this does not explain why this strain, in particular, shows greater sensitivity to the psychomotor effects of cocaine in this context. The mechanisms by which drug effects interact with context to result in behavioral differences remain to be determined. Further experiments are necessary to replicate these results and to gain a better understanding of this phenomenon in BALB mice.

Our observation that D2 mice did not exhibit significant place preference under our assay conditions aligns with previous reports using higher doses of cocaine (32 $\mathrm{mg} / \mathrm{kg}$ [4]; $30 \mathrm{mg} / \mathrm{kg}$ [14]) and deviates from others reporting place conditioning in response to moderate doses $(10 \mathrm{mg} / \mathrm{kg}[14])$. Taken together, these studies support dose-dependent place preference in D2 mice. However, modification of experimental parameters can also influence place conditioning and should be carefully 
considered when planning experiments and reporting results [14].

\section{Conclusions}

This study expands upon current literature in the field, describing cocaine-induced conditioned place preference in three strains/substrains for which it had not previously been reported. Further, we have also shown context-dependent locomotor sensitization in response to cocaine in BALB/cJ mice. Of the strains included in our study, $\mathrm{B} 6$ and $\mathrm{C} 3 \mathrm{H}$ emerge as the most appropriate for the study of responses to cocaine, as these mice develop place preference and show acute locomotor activation and sensitization. The use of strains such as FVB and BALB may benefit studies aiming to dissociate the mechanisms underlying these cocaine-induced behaviors. These results highlight the importance of considering both context and genetic background in the analysis of cocaine-induced behaviors.

Much remains unknown regarding the neural circuitry and genetic mechanisms underlying drug addiction. The tremendous genetic variability among inbred mouse strains and our ability to model aspects of addiction with various behavioral paradigms, such as CPP, will eventually lead to the identification of genes and gene networks that influence addiction pathways in the brain and promise to have a profound effect on the treatment of addiction in the clinic.

\section{Acknowledgements}

The authors wish to thank Dr. Christopher Cunningham for helpful discussions on both the data and manuscript. This research was supported by funding from NIH NIDA Grants DA022392 and DA023690 to LMT and a Novartis Grant SFP-1406 from the Genomics Institute of the Novartis Research Foundation.

Acknowledgement of grant funding

This work was sponsored by grants DA022392 and DA023690 from the/ National Institute on Drug Abuse/National Institutes of Health.

\section{Author details}

'Department of Psychiatry, University of North Carolina, Chapel Hill, NC, USA. ${ }^{2}$ Genomics Institute of the Novartis Research Foundation, San Diego, CA, USA

\section{Authors' contributions}

AFED contributed to the statistical analysis and the drafting of the manuscript. LGB carried out the behavioral testing and contributed to the study design. LMT conceived of the study, participated in its design and coordination, contributed to the statistical analysis and helped to draft the manuscript. All authors read and approved the final manuscript.

\section{Competing interests}

The authors declare that they have no competing interests.

Received: 25 April 2011 Accepted: 1 August 2011

Published: 1 August 2011

\section{References}

1. Uhl GR, Elmer Gl, LaBuda MC, Pickens RW: Genetic Influences in Drug Abuse. In Psychopharmacology: The fourth generation of progress. Edited by: Bloom FE, Kupfer DJ. New York: Raven Press; 1995:1793-1806.
2. Crabbe JC, Belknap JK, Buck KJ: Genetic animal models of alcohol and drug abuse. Science 1994, 264:1715-1723.

3. George FR, Goldberg SR: Genetic approaches to the analysis of addiction processes. Trends Pharmacol Sci 1989, 10:78-83.

4. Seale TW, Carney JM: Genetic determinants of susceptibility to the rewarding and other behavioral actions of cocaine. J Addict Dis 1991, 10:141-162.

5. Cunningham $\mathrm{CL}$, Gremel CM, Groblewski PA: Drug-induced conditioned place preference and aversion in mice. Nat Protoc 2006, 1:1662-1670.

6. Sanchis-Segura C, Spanagel R: Behavioural assessment of drug reinforcement and addictive features in rodents: an overview. Addict Biol 2006, 11:2-38

7. Gerasimov MR, Schiffer WK, Gardner EL, Marsteller DA, Lennon IC, Taylor SJ, Brodie JD, Ashby CR, Dewey SL: GABAergic blockade of cocaineassociated cue-induced increases in nucleus accumbens dopamine. Eur J Pharmacol 2001, 414:205-209.

8. Self DW, Nestler EJ: Relapse to drug-seeking: neural and molecular mechanisms. Drug Alcohol Depend 1998, 51:49-60.

9. Bardo MT, Bevins RA: Conditioned place preference: what does it add to our preclinical understanding of drug reward? Psychopharmacology (Berl) 2000, 153:31-43

10. Ruiz-Durantez E, Hall SK, Steffen C, Self DW: Enhanced acquisition of cocaine self-administration by increasing percentages of $\mathrm{C} 57 \mathrm{BL} / 6 \mathrm{~J}$ genes in mice with a nonpreferring outbred background. Psychopharmacology (Berl) 2006, 186:553-560.

11. Griffin WC, Randall PK, Middaugh LD: Intravenous cocaine selfadministration: individual differences in male and female $\mathrm{C} 57 \mathrm{BL} / 6 \mathrm{~J}$ mice. Pharmacol Biochem Behav 2007, 87:267-279.

12. Festa ED, Quinones-Jenab V: Gonadal hormones provide the biological basis for sex differences in behavioral responses to cocaine. Horm Behav 2004, 46:509-519.

13. Ambrose-Lanci LM, Sterling RC, Van Bockstaele EJ: Cocaine withdrawalinduced anxiety in females: impact of circulating estrogen and potential use of delta-opioid receptor agonists for treatment. J Neurosci Res 88:816-824.

14. Cunningham CL, Dickinson SD, Grahame NJ, Okorn DM, McMullin CS: Genetic differences in cocaine-induced conditioned place preference in mice depend on conditioning trial duration. Psychopharmacology (Berl) 1999, 146:73-80

15. Jones $B C$, Tarantino LM, Rodriguez LA, Reed CL, McClearn GE, Plomin R, Erwin VG: Quantitative-trait loci analysis of cocaine-related behaviours and neurochemistry. Pharmacogenetics 1999, 9:607-617.

16. Miner LL, Marley RJ: Chromosomal mapping of the psychomotor stimulant effects of cocaine in BXD recombinant inbred mice. Psychopharmacology (Berl) 1995, 122:209-214.

17. Phillips TJ, Huson MG, McKinnon CS: Localization of genes mediating acute and sensitized locomotor responses to cocaine in BXD/Ty recombinant inbred mice. J Neurosci 1998, 18:3023-3034.

18. Belzung C, Barreau S: Differences in drug-induced place conditioning between BALB/C and C57BI/6 mice. Pharmacol Biochem Behav 2000, 65:419-423.

19. Bardo MT, Rowlett JK, Harris MJ: Conditioned place preference using opiate and stimulant drugs: a meta-analysis. Neurosci Biobehav Rev 1995 19:39-51.

20. Orsini C, Bonito-Oliva A, Conversi D, Cabib S: Susceptibility to conditioned place preference induced by addictive drugs in mice of the $\mathrm{C} 57 \mathrm{BL} / 6$ and DBA/2 inbred strains. Psychopharmacology (Berl) 2005, 181:327-336

21. Kuzmin A, Johansson B: Reinforcing and neurochemical effects of cocaine: differences among C57, DBA, and 129 mice. Pharmacol Biochem Behav 2000, 65:399-406.

22. Ruth JA, Ullman EA, Collins AC: An analysis of cocaine effects on locomotor activities and heart rate in four inbred mouse strains. Pharmacol Biochem Behav 1988, 29:157-162.

23. Hanania T, McCreary AC, Salaz DO, Lyons AM, Zahniser NR: Differential regulation of cocaine-induced locomotor activity in inbred long-sleep and short-sleep mice by dopamine and serotonin systems. Eur $J$ Pharmacol 2004, 502:221-231.

24. Tolliver BK, Carney JM: Sensitization to stereotypy in DBA/2J but not C57BL/6J mice with repeated cocaine. Pharmacol Biochem Behav 1994 48:169-173. 
25. Schlussman SD, Ho A, Zhou Y, Curtis AE, Kreek MJ: Effects of "binge" pattern cocaine on stereotypy and locomotor activity in C57BL/6J and 129/J mice. Pharmacol Biochem Behav 1998, 60:593-599.

26. Zombeck JA, Swearingen SP, Rhodes JS: Acute locomotor responses to cocaine in adolescents vs. adults from four divergent inbred mouse strains. Genes Brain Behav 2010, 9:892-898.

27. Zhang Y, Mantsch JR, Schlussman SD, Ho A, Kreek MJ: Conditioned place preference after single doses or "binge" cocaine in C57BL/6J and 129/J mice. Pharmacol Biochem Behav 2002, 73:655-662.

28. Miner LL: Cocaine reward and locomotor activity in C57BL/6J and 129/ SvJ inbred mice and their F1 cross. Pharmacol Biochem Behav 1997, 58:25-30.

29. Schlussman SD, Zhang Y, Kane S, Stewart CL, Ho A, Kreek MJ: Locomotion, stereotypy, and dopamine D1 receptors after chronic "binge" cocaine in C57BL/6J and 129/J mice. Pharmacol Biochem Behav 2003, 75:123-131.

30. Crabbe JC, Phillips TJ, Buck KJ, Cunningham CL, Belknap JK: Identifying genes for alcohol and drug sensitivity: recent progress and future directions. Trends Neurosci 1999, 22:173-179.

31. Podhorna J, Brown RE: Strain differences in activity and emotionality do not account for differences in learning and memory performance between C57BL/6 and DBA/2 mice. Genes Brain Behav 2002, 1:96-110.

32. Mhyre TR, Chesler EJ, Thiruchelvam M, Lungu C, Cory-Slechta DA, Fry JD, Richfield EK: Heritability, correlations and in silico mapping of locomotor behavior and neurochemistry in inbred strains of mice. Genes Brain Behav 2005, 4:209-228.

33. Wenger GR: The role of control activity levels in the reported strain differences to the behavioral effects of drugs in mice. Pharmacol Biochem Behav 1989, 32:241-247.

34. Moore TO, June HL, Lewis MJ: Ethanol-induced stimulation and depression on measures of locomotor activity: effects of basal activity levels in rats. Alcohol (Fayetteville, NY 1993, 10:537-540.

35. Cunningham CL: Localization of genes influencing ethanol-induced conditioned place preference and locomotor activity in BXD recombinant inbred mice. Psychopharmacology (Berl) 1995, 120:28-41.

36. Vezina $P$, Stewart J: Morphine conditioned place preference and locomotion: the effect of confinement during training. Psychopharmacology (Berl) 1987, 93:257-260.

37. Gremel CM, Cunningham CL: Role of test activity in ethanol-induced disruption of place preference expression in mice. Psychopharmacology (Berl) 2007, 191:195-202.

38. Robinson TE, Berridge KC: The neural basis of drug craving: an incentivesensitization theory of addiction. Brain Res Brain Res Rev 1993, 18:247-291.

39. Wise RA, Bozarth MA: A psychomotor stimulant theory of addiction. Psychol Rev 1987, 94:469-492.

40. Reith ME, Selmeci G: Cocaine binding sites in mouse striatum, dopamine autoreceptors, and cocaine-induced locomotion. Pharmacol Biochem Behav 1992, 41:227-230.

41. Wiener HL, Reith ME: Correlation between cocaine-induced locomotion and cocaine disposition in the brain among four inbred strains of mice. Pharmacol Biochem Behav 1990, 36:699-701.

42. Reith ME, Benuck M, Lajtha A: Cocaine disposition in the brain after continuous or intermittent treatment and locomotor stimulation in mice. J Pharmacol Exp Ther 1987, 243:281-287.

43. Reith ME: Effect of repeated administration of various doses of cocaine and WIN 35,065-2 on locomotor behavior of mice. Eur J Pharmacol 1986, 130:65-72.

44. Koff JM, Shuster L, Miller LG: Chronic cocaine administration is associated with behavioral sensitization and time-dependent changes in striatal dopamine transporter binding. J Pharmacol Exp Ther 1994, 268:277-282.

45. Ito S, Mori T, Namiki M, Suzuki T, Sawaguchi T: Complicated interaction between psychostimulants and morphine in expression of phenotype of behavior in the dopaminergic system of BALB/C mice. Journal of pharmacological sciences 2007, 105:326-333.

46. Shuster L, Yu G, Bates A: Sensitization to cocaine stimulation in mice. Psychopharmacology (Berl) 1977, 52:185-190.

47. Badiani A, Robinson TE: Drug-induced neurobehavioral plasticity: the role of environmental context. Behav Pharmacol 2004, 15:327-339.

48. Badiani A, Browman KE, Robinson TE: Influence of novel versus home environments on sensitization to the psychomotor stimulant effects of cocaine and amphetamine. Brain Res 1995, 674:291-298.
49. Badiani A, Cabib S, Puglisi-Allegra S: Chronic stress induces straindependent sensitization to the behavioral effects of amphetamine in the mouse. Pharmacol Biochem Behav 1992, 43:53-60.

50. Caprioli D, Celentano M, Paolone G, Badiani A: Modeling the role of environment in addiction. Prog Neuropsychopharmacol Biol Psychiatry 2007, 31:1639-1653.

51. Rivet JM, Stinus L, LeMoal M, Mormede P: Behavioral sensitization to amphetamine is dependent on corticosteroid receptor activation. Brain Res 1989, 498:149-153.

52. Willner P, Papp M, Cheeta S, Muscat R: Environmental influences on behavioural sensitization to the dopamine agonist quinpirole. Behav Pharmacol 1992, 3:43-50.

doi:10.1186/1744-9081-7-29

Cite this article as: Eisener-Dorman et al:: Cocaine locomotor activation, sensitization and place preference in six inbred strains of mice. Behavioral and Brain Functions 2011 7:29.

\section{Submit your next manuscript to BioMed Central and take full advantage of:}

- Convenient online submission

- Thorough peer review

- No space constraints or color figure charges

- Immediate publication on acceptance

- Inclusion in PubMed, CAS, Scopus and Google Scholar

- Research which is freely available for redistribution

Submit your manuscript at www.biomedcentral.com/submit
C) Biomed Central 